\title{
Diagnóstico da capacitação organizacional para 0 trabalho em equipe
}

Patricia de Sá Freire ${ }^{1}$ Roseli Jenoveva $\mathrm{Neto}^{2}$ Gilberto Montibeller Filho ${ }^{3}$ Fernando José Spanhol ${ }^{4}$

\section{RESUMO}

A pesquisa visou diagnosticar o estágio de capacitação para aprendizagem de uma empresa brasileira do setor de comunicação. Para tanto, o estudo buscou apoio nas teorias de autores clássicos e contemporâneos, como Vygotsky (2005) e a construção social da aprendizagem e, Nonaka e Takeuchi (1997) e a construção do conhecimento. Definiram-se variáveis de análise a partir das técnicas para a "empresa que aprende" de Senge (2006). Realizou-se pesquisa descritiva predominantemente qualitativa mediante entrevista e análise documental, e quantitativa, utilizando-se questionários com os funcionários para obtenção de dados primários. Concluiu-se que o grupo tem construído valor na disciplina Domínio Pessoal ao incentivar e apoiar os estudos e o crescimento individual; contudo, para se capacitar ao enfrentamento da globalização, precisa-se dar mais atenção à comunicação interna e aos trabalhos colaborativos. Com isso, constrói-se coerência entre as estratégias e as ações, o que, por sua vez, também contribuirá para eliminar os bloqueios existentes no grupo para desenvolver as outras disciplinas essenciais. Este estudo, além do diagnóstico da capacitação organizacional para a aprendizagem, destaca uma contribuição metodológica com seu questionário e o gráfico Radar, que facilita o entendimento do diagnóstico e a discussão de soluções para dificuldades diagnosticadas.

Palavras-Chave: Diagnóstico Organizacional. Aprendizagem Organizacional. Construção do Conhecimento.

\section{INTRODUÇÃO}

Os parâmetros do mundo capitalista sofreram mudanças significativas a partir da década de 1980. Os avanços tecnológicos da informação e comunicação levaram o ambiente organizacional para um mundo de vivências que exige decisões rápidas e cada vez mais complexas, impondo-se novos padrões que interferiram nas estruturas e estratégias competitivas, no processo produtivo e, consequentemente, nas características da cultura organizacional.

Garantir a sobrevivência no mercado global significa adaptar-se rapidamente ao novo contexto mesmo que mais complexo, acompanhando e promovendo a inovação. Aprender faz a diferença no mundo globalizado e respeitar o papel da aprendizagem no crescimento da organização significa desenvolver processos que valorizem as pessoas, causando seu crescimento como indivíduos e como participantes do grupo, reconhecendo o papel da cultura organizacional como apoio à acelerada carga de informações advindas da presença globalizada e das rápidas e complexas mudanças tecnológicas.

\footnotetext{
${ }^{1}$ Doutora. Universidade do Extremo Sul Catarinense (UNESC). patriciadesafreire@gmail.com.

${ }^{2}$ Mestre. Universidade do Extremo Sul Catarinense (UNESC). roseli@unesc.net

${ }^{3}$ Doutor. Universidade do Extremo Sul Catarinense (UNESC). montibeller@unesc.net

${ }^{4}$ Doutor. Universidade Federal de Santa Catarina (UFSC). spanhol@led.ufsc.br
} 
Wood Jr. e Zuffo (1998) chamam essa fase de hipercompetição pela amplitude e velocidade das dinâmicas das inter-relações dos atores em âmbito mundial. As vantagens competitivas são efêmeras, e o ciclo de vida dos produtos é curto, instável e imprevisível. Explorando o conceito de que as organizações vêm se desenvolvendo com base em características culturais que as bem posicione perante os concorrentes, Hayes et al (2008) destacam que esse processo envolve mais do que apenas incrementar seu desempenho em dimensões específicas, como custos, qualidade e flexibilidade. Devem-se incorporar novas capacitações que abram novas oportunidades estratégicas, que por si só realimentarão as estratégias competitivas.

Do mesmo modo, o crescimento da complexidade dos sistemas organizacionais tem intensificado as exigências quanto à qualidade do aprendizado individual e da motivação para a busca de resultados para todos. Porém, cada vez mais as consequências das ações individuais, ou mesmo os resultados das contribuições de um grupo independentemente de trabalho, não são facilmente identificadas.

Corroborando com essas ideias, Senge (2006) afirma que as empresas, para se manterem competitivas, devem começar a entender o funcionamento e a busca de equilíbrio de seu próprio sistema interno, promovendo a sustentação contínua desse equilíbrio, mesmo, e apesar das mudanças provocadas pela complexidade do meio. Visto aqui sistema, não como tecnologia criada e controlada pelo sujeito, mas sim, como definem Maturana e Varela (2007), um sistema natural em fluxo contínuo de autopoiese (autoorganização), com suas trocas e buscas constantes do estado de equilíbrio com o meio entorno. Um sistema dinâmico e inteligente que, ao perceber as características do ambiente, se reestrutura internamente, preparando-se para dialogar e conviver produtivamente.

Para enfrentar as dificuldades das transformações deste mundo globalizado, o caminho é eliminar as dificuldades das empresas em construir capacidade interna para enfrentar os problemas de valorização e integração cultural e humana. Ou seja, ao desenvolver uma empresa aberta, a construção de novos conhecimentos - aberta a aprender -, serão eliminados paradigmas antigos dominados por modelos mentais prejudiciais às mudanças.

Assim, torna-se importante para o enfrentamento das incertezas provocadas pela globalização o diagnóstico do estágio de capacitação interna em que se encontra a organização. Para tal, foi escolhido por acessibilidade um grupo brasileiro de comunicação "ComC", por meio das percepções de seus funcionários. 0 nome "ComC" é fictício para manter em estrita reserva a identidade da empresa pesquisada.

\subsection{Objetivo geral}

Diagnosticar o Estágio de Capacitação Organizacional para a Aprendizagem de pequena empresa brasileira.

\section{A EMPRESA QUE APRENDE}

A teoria histórico-social do pensador e pesquisador russo sociointeracionista Vygotsky (2005) considera que a construção do conhecimento pelo sujeito se faz a partir de sua interação com o meio, sendo esta a base para o seu desenvolvimento. 0 conceito de mediação das teorias de Vygotsky (2005) define que o objeto somente faz sentido para o sujeito quando intermediado pelo meio à sua volta, permitindo-lhe, assim, interpretar os símbolos que esses objetos representam.

Mas esse referencial cultural hoje se encontra espalhado em um sistema complexo (e mutável), construído sob os desafios da globalização, e a busca de significações e traduções acaba por superar as competências limitadas do próprio sujeito. A complexidade efetiva está relacionada à natureza do sistema e caracteriza-se pela aprendizagem e pela evolução, exigindo a habilidade de distinguir os padrões de regularidade e aleatoriedade que ocorrem no próprio sistema.

De acordo com Senge (2006), para se alcançar o sucesso da construção de conhecimentos sob a complexidade das regras da globalização, exige-se a participação proativa de todos os participantes do sistema, fazendo-o integrado e integrante para que se incluam os valores dos aprendizados individuais e de grupo. 0 autor desenvolveu técnicas agrupadas em cinco disciplinas: Domínio pessoal, Domínio dos modelos mentais, Visão compartilhada, Aprendizado em equipe e Pensamento sistêmico. Com o objetivo de promover um impacto significativo e mensurável nos resultados, as cinco disciplinas compõem um conjunto de práticas de aprendizagem que permitem ao sujeito e ao grupo do qual faz parte modificarem caminhos, adquirirem novas habilidades, descobrirem níveis de autoconsciência e conquistar conhecimentos e experiências.

A estrutura conceitual desenvolvida por Nonaka e Takeuchi (1997) integra as visões tradicionais e não 
tradicionais de construção do conhecimento organizacional, em sua dimensão epistemológica e ontológica. Pela dimensão ontológica, o conhecimento só é construído pelo indivíduo e, dentro de uma comunidade de interação, consegue-se ampliar e cristalizar esse conhecimento como sendo organizacional, atingindo níveis inter-organizacionais. Pela dimensão epistemológica, percebe-se que grande parte dos conhecimentos são frutos do esforço voluntário de cada sujeito em lidar com o mundo à sua volta e, para que se possa gerenciálos na organização, é importante a conversão do conhecimento de tácito para explícito. A estrutura conceitual desenvolvida por Nonaka e Takeuchi (1997) integra as visões tradicionais e não tradicionais de construção do conhecimento organizacional, em sua dimensão epistemológica e ontológica. Pela dimensão ontológica, o conhecimento só é construído pelo indivíduo e, dentro de uma comunidade de interação, consegue-se ampliar e cristalizar tal conhecimento como sendo organizacional, atingindo níveis inter-organizacionais.

Senge (2006) propõe um caminho no qual a organização consiga construir um modus operandi que integre verdadeiramente as partes para o alcance de um objetivo comum a todos, o sucesso da empresa. E, para trilhar o referido caminho, ele propõe que a organização, por ela mesma, abra-se ao aprendizado contínuo, recriando-se continuamente, transmutando-se de uma "organização que visa apenas sobreviver" para uma organização inteligente com capacidade de aprender rapidamente, prontificando-se a enfrentar os desafios da dinâmica acelerada do mercado cada vez mais competitivo - expandindo sua capacidade de criar seu próprio futuro (SENGE, 2006, p. 47).

\subsection{As Disciplinas Essenciais}

Senge (2006) sugere que o crescimento integrado e integrante necessário se processa a partir do desenvolvimento de técnicas organizacionais agrupadas em quatro disciplinas essenciais: Domínio Pessoal, Modelos Mentais, Visão Compartilhada, Aprendizado em Equipe.

A disciplina Domínio Pessoal define que as pessoas concretizam os resultados mais importantes em suas vidas, comprometendo-se com seu próprio aprendizado. Senge (2006) destaca a importância dessa busca individual de resultados objetivamente definidos, para que se aprenda a ver a realidade com clareza, sem se perder no caminho, não aceitando situações-problema que tirem do propósito. Desenvolver tal competência "significa encarar a vida como um trabalho criativo, vivê-la da perspectiva criativa, e não reativa" (SENGE, 2006, p. 169). A organização acelera seu crescimento quando incentiva o crescimento e a aprendizagem de seus funcionários, pois o pleno desenvolvimento de seus funcionários aprofunda a "visão pessoal" de mundo, de futuro de esforços necessários para o alcance do futuro pretendido (SENGE, 2006, p. 173). Esta disciplina exige que os líderes imponham à organização o comprometimento absoluto inteiro e intrínseco com o bem-estar de seus funcionários, mas sem eliminar a tensão criativa da busca por uma visão de futuro.

Os Modelos Mentais são paradigmas construídos ao longo da vida, "são pressupostos profundamente arraigados, generalizações ou mesmo imagens que influenciam nossa forma de ver o mundo e de agir" (SENGE, 2006, p. 173). E, para que as imagens internas sobre o mundo sejam aperfeiçoadas, os modelos mentais precisam ser identificados, desconstruídos e reconstruídos, a fim de que as mudanças e inovações sejam possíveis. 0 enraizamento provocado pelos modelos mentais limita as ações à zona de conforto, não sendo possível a identificação do que deveria ser discutido, analisado e reconstruído para que se permita criar o novo. Trabalhar os modelos mentais é um processo que "começa por virar o espelho para dentro; aprender a desenterrar nossas imagens internas do mundo, a levá-las a superfície e mantê-las sob rigorosa análise", que só pode ser realizado com Diálogos. Momentos de socialização que propiciam "conversas ricas em aprendizados, que equilibrem indagação e argumentação, em que as pessoas exponham de forma eficaz seus próprios pensamentos e estejam abertas à influência dos outros" (SENGE, 2006, p. 42).

A disciplina de Visão Compartilhada estimula o engajamento do grupo na busca de uma imagem compartilhada do futuro que quer criar, pois, quando se conquista uma visão genuína de aonde o grupo quer chegar, em oposição à famosa declaração de missão, conectam-se verdadeiramente os indivíduos em prol de uma aspiração comum, e as pessoas passam a dar tudo de si e aprender, não porque são obrigadas, mas porque querem. A aplicação desta disciplina envolve as "habilidades de descobrir imagens de futuro compartilhadas que estimulem o compromisso genuíno e o envolvimento, em lugar da mera aceitação" (SENGE, 2006, p. 43). Porém, a organização só encontrará sucesso nessa busca quando cada indivíduo acreditar que a realidade que será vivenciada no futuro é construída por cada um e pode-se alterá-la a partir de ações realizadas no presente.

Aprendizagem em Equipe é a capacidade de perceber o grupo como "a unidade de aprendizagem fundamental nas organizações modernas" e, por isso, explora as aptidões coletivas, sabendo-se que a "inteligência da equipe excede a inteligência de seus membros, e nos quais o grupo desenvolve capacidades excepcionais de ação coordenada" (SENGE, 2006, p. 43). A força desta disciplina é o diálogo, pois por meio 
deste se reconhecem os padrões de defesa utilizados pelas pessoas para interagir, o que acaba por dificultar a aprendizagem. Resumidamente, Senge (2006, p. 263) explica que esta disciplina significa um "processo de alinhamento e desenvolvimento da capacidade da equipe de criar resultados que seus membros realmente desejam".

\section{QUINTA DISCIPLINA}

Com o objetivo de promover um impacto significativo e mensurável nos resultados organizacionais, as disciplinas essenciais compõem um conjunto de práticas de aprendizagem que permitem modificar caminhos, adquirir novas habilidades, descobrir níveis de autoconsciência e conquistar conhecimentos e experiências. Tais competências, quando existentes, propiciam o nascimento da quinta disciplina, batizada por Senge (2006) de Pensamento Sistêmico.

O Pensamento Sistêmico ajuda a identificar o processo detalhado de como foi criado o que se tem no momento, pois permite olhar a empresa como um sistema integrado e integrante, onde todos estão "conectados por fios invisíveis de ações inter-relacionadas, que muitas vezes levam anos para manifestar seus efeitos umas sobre as outras"(SENGE, 2006, p. 258). 0 autor apresenta o pensamento sistêmico como um quadro de referência conceitual, um conjunto de conhecimentos e ferramentas que consegue apontar os padrões vivenciados nas relações - os inter-relacionamentos em vez de cadeias lineares de causa-efeito - vendo os processos de mudança em vez de simples fotos instantâneas, o que facilita a identificação dos pontos a serem alterados.

O fio condutor que faz a ligação entre os indivíduos e grupos para propiciar o desenvolvimento da quinta disciplina é o diálogo como rotina. Em oposto às ordens top down, o diálogo faz com que os envolvidos acessem um grande conjunto de signos e significados comuns, que não acessariam individualmente. Assim, o todo organiza as partes, em vez de se tentar encaixar as partes em um todo já previamente estruturado (SENGE, 2006).

\section{PROCEDIMENTOS METODOLÓGICOS}

Para proporcionar uma maior profundidade de análise, a partir da compreensão do contexto do problema e oferecer um panorama mais amplo sobre a situação (MALHOTRA, 2001), a abordagem metodológica desta pesquisa caracteriza- se como um estudo descritivo qualitativo feito mediante entrevistas e análise documental. A pesquisa utilizou-se de dados quantitativos, com a aplicação de questionários para a obtenção dos dados primários. A análise dos dados caracteriza-se, predominantemente, como qualitativa descritiva e de conteúdo. A análise de conteúdo foi considerada, nesta pesquisa, como uma técnica para o tratamento de dados que visa identificar o que está sendo dito a respeito de determinado tema. (VERGARA, 2005)

A amostra, qualificada pelos critérios objetivos de seleção dos indivíduos, foi definida por acessibilidade. Para os quase 150 funcionários distribuídos por diferentes cidades do Estado brasileiro no qual está situada a matriz, foram enviados os questionários eletronicamente por um dos pesquisadores e recebido preenchidos 43; quatro destes estavam preenchidos incorretamente, tendo de ser anulados. Dessa forma, constituem amostra final desta pesquisa 39 funcionários da empresa em estudo.

Como técnicas de coleta de dados, foram utilizadas entrevistas com o dono da empresa, e suas respostas serviram como base para as afirmativas apresentadas no questionário semiestruturado enviado a todos os funcionários. As variáveis foram classificadas com base nas disciplinas definidas por Senge (2006) para servirem de fundamento para a construção dos questionários, a análise e alcance dos objetivos desta pesquisa, e formadas por características específicas operacionalizadas por meio de indicadores.

O questionário foi construído a partir de afirmativas fechadas que investigaram o grau de concordância e discordância pela escala Likert de cinco pontos. Esse instrumento constou com 25 questões divididas pelas quatro disciplinas essenciais da seguinte maneira: Domínio Pessoal, com seis questões; Modelo Mental, com sete questões; Visão Compartilhada, com cinco questões; e Aprendizagem em Equipe, com sete questões. 0 questionário ainda continha duas perguntas que, dentre a disciplina de Domínio Pessoal, visavam levantar se, na percepção dos funcionários, a empresa incentiva o crescimento profissional, quais meios a empresa oferece para que os funcionários possam estudar e continuar aprendendo. Ainda, foi questionada qual a motivação para continuar trabalhando na empresa.

\section{RESULTADOS DA PESQUISA}


Apresentam-se a seguir os resultados da pesquisa, por meio da interpretação dos dados, de acordo com as cinco disciplinas sugeridas por Senge (2006).

Domínio Pessoal: Pelas respostas ao questionário apresentado na Tabela 1, pode-se afirmar que a quase totalidade, 96\%, dos funcionários da empresa estudada (com desvio padrão de 7,63) acredita que o seu trabalho é importante para o alcance do sucesso de sua área (média de 4,55); a grande maioria, 80\%, define seu trabalho como desafiador o que exige constante atualização (média de 4,13).

Mesmo tendo ficado acima da média $(4,19)$, a afirmativa de que os funcionários lidam bem com as mudanças e, por isso, estas são bem-vindas, os respondentes não concordaram que os acontecimentos inesperados não provocam reações negativas na sua equipe de trabalho (média baixa de 2,74).

Uma das médias mais baixas foi estabelecida $(2,68)$ nesta etapa do questionário que analisa a disciplina Domínio Pessoal, em que se pode sugerir que os funcionários não estão sempre envolvidos com estudos para crescerem profissionalmente. Entretanto, mostra-se um baixo desvio padrão $(2,68)$ demonstrando as diferentes opiniões quanto ao assunto e, ainda, 55\% dos respondentes marcaram que não concordam nem discordam com a afirmativa, podendo significar que, na verdade, não sabem perceber esta característica cultural.

A grande maioria dos entrevistados (84\%) confirmam que a empresa incentiva o seu crescimento profissional.

Quando perguntados se a empresa oferece meios para que o funcionário possa estudar e continuar aprendendo, 23\% dos entrevistados afirmaram que na empresa existe oportunidade de aprender com os profissionais mais experientes; $19 \%$ disseram que, além do salário, a empresa ajuda a pagar os custos financeiros dos estudos; outros 19\% afirmaram que a empresa promove cursos dentro da empresa; e ainda outros 19\% diz que a empresa lhes concede facilidades de horários para que possam se dedicar aos estudos. E, ainda, há 10\% que dizem que a empresa paga cursos fora da própria empresa. Assim, somam-se $90 \%$ dos respondentes que destacam o apoio da empresa para seu crescimento profissional.

Porém, vale apontar que $6 \%$ das respostas dizem que os funcionários mais próximos do presidente têm conhecimento da possibilidade de ter apoio da empresa para frequentar cursos e universidades, e os novos funcionários e os mais distantes em hierarquia pouco ou nada sabem sobre essa possibilidade, o que pode significar a não institucionalização do benefício ou fraca comunicação interna.

E, talvez por isso, o trabalho não seja especializado (média de 2,87) e possam ser os funcionários substituídos com mais facilidade, pelo menos na percepção dos próprios funcionários respondentes.

Tabela 1 - Respostas aos questionários relacionados ao Domínio Pessoal

\begin{tabular}{|c|c|c|c|c|c|c|c|}
\hline DOMÍNIO PESSOAL & Média & $\begin{array}{l}\text { Desvio } \\
\text { padrão }\end{array}$ & 1 & 2 & 3 & 4 & 5 \\
\hline & 3,53 & & & & & & \\
\hline 0 seu trabalho é desafiador exigindo-Ihe atualização constante & 4,13 & 5,49 & $0 \%$ & $3 \%$ & $16 \%$ & $45 \%$ & $35 \%$ \\
\hline 0 seu trabalho é importante para o alcance do sucesso de sua área & 4,55 & 7,63 & $0 \%$ & $3 \%$ & $0 \%$ & $35 \%$ & $61 \%$ \\
\hline $\begin{array}{l}\text { Seu trabalho é especializado, por isso não seria fácil substituírem você em } \\
\text { suas funções, caso necessário }\end{array}$ & 2,87 & 2,04 & $16 \%$ & $23 \%$ & $29 \%$ & $23 \%$ & $10 \%$ \\
\hline Seus colegas estão sempre estudando para crescerem profissionalmente & 2,68 & 5,74 & $13 \%$ & $19 \%$ & $55 \%$ & $13 \%$ & $0 \%$ \\
\hline Você lida bem com as mudanças. Elas são bem-vindas & 4,19 & 6,24 & $0 \%$ & $3 \%$ & $10 \%$ & $52 \%$ & $35 \%$ \\
\hline $\begin{array}{l}\text { Os acontecimentos inesperados não provocam reações negativas na sua } \\
\text { equipe de trabalho }\end{array}$ & 2,74 & 4,35 & $6 \%$ & $42 \%$ & $26 \%$ & $23 \%$ & $3 \%$ \\
\hline
\end{tabular}

Fonte: Elaborado pelos autores (2013)

Modelos Mentais: 0 resultado apresentado na Tabela 2, referente a esta parte do questionário que pretende diagnosticar qual o Modelo Mental da empresa voltado para o aprendizado, destaca que é muito clara a hierarquia que determina os papéis de presidente, diretores, gerentes, chefias e funcionários (a maior média desta parte do questionário - 4,06), mas que é fácil a comunicação vertical (um pouco acima da média - 3,45) e horizontal na empresa (pouco acima da média - 3,42). Vale atentar ao baixo desvio padrão das questões relacionadas à facilidade de comunicação, pois a facilidade de comunicação entre funcionários e líderes aponta um desvio padrão de 2,71, e a facilidade de comunicação entre áreas tem 3,42 de desvio 
padrão, significando falta de consenso entre os respondentes.

Quanto à comunicação verticalizada, vale apontar a imensa dificuldade em levantar, relacionar e organizar os endereços de e-mails de todos os funcionários da empresa. Não existia, nem com a presidência nem com as diretorias, uma relação de endereços de e-mails confiável para que se pudesse realizar uma comunicação formal entre líderes e funcionários, entre o departamento de RH e todos os colaboradores, e entre os próprios grupos de colaboradores. Após o recebimento da última lista considerada finalizada pela empresa, os pesquisadores ainda receberam a devolução de um e-mail afirmando não fazer parte da empresa e, por isso, não entendiam o porquê de estar recebendo o questionário. Além de outras pessoas solicitando o questionário por se dizerem funcionários da empresa e mesmo assim não fazerem parte da listagem.

Bem abaixo da média aparecem as afirmativas sobre a falta de motivação dos funcionários a criar e sugerir ideias novas (a mais baixa desta disciplina - média de 3,00), o que pode ser pela falta de políticas da empresa para incentivo à sugestão de novas ideias (média de 3,03). Mesmo não havendo consenso (desvio padrão de 4,62), ficou abaixo da média, definindo que a empresa não está aberta à sugestão de alterações de processos de rotina $(3,23)$, inclusive os recém-contratados não parecem ser incentivados a participar e contribuir com opiniões e sugestões $(3,13)$.

Tabela 2 - Respostas aos questionários relacionados ao Modelos Mentais

\begin{tabular}{|c|c|c|c|c|c|c|c|}
\hline MODELOS MENTAIS & Média & $\begin{array}{l}\text { Desvio } \\
\text { padrão }\end{array}$ & 1 & 2 & 3 & 4 & 5 \\
\hline & 3,33 & & & & & & \\
\hline É fácil a comunicação vertical, entre funcionários e líderes & 3,45 & 2,71 & $3 \%$ & $23 \%$ & $23 \%$ & $29 \%$ & $23 \%$ \\
\hline É fácil a comunicação horizontal, entre as áreas & 3,42 & 3,43 & $3 \%$ & $16 \%$ & $32 \%$ & $32 \%$ & $16 \%$ \\
\hline $\begin{array}{l}\text { É muito clara a hierarquia - presidente, diretores, gerentes, chefias e } \\
\text { funcionários }\end{array}$ & 4,06 & 4,96 & $0 \%$ & $13 \%$ & $10 \%$ & $35 \%$ & $42 \%$ \\
\hline $\begin{array}{l}\text { A empresa está aberta a sugestões quanto a alterações de processos } \\
\text { de rotina }\end{array}$ & 3,23 & 4,62 & $3 \%$ & $16 \%$ & $42 \%$ & $32 \%$ & $6 \%$ \\
\hline Você sente seus colegas motivados a criar e sugerir ideias novas & 3,00 & 4,62 & $10 \%$ & $16 \%$ & $39 \%$ & $35 \%$ & $0 \%$ \\
\hline $\begin{array}{l}\text { Existem políticas da empresa para incentivar a sugestão de novas } \\
\text { ideias }\end{array}$ & 3,03 & 4,07 & $10 \%$ & $16 \%$ & $45 \%$ & $19 \%$ & $10 \%$ \\
\hline $\begin{array}{l}\text { Os recém-contratados são incentivados a participar e contribuir com } \\
\text { opiniões e sugestões }\end{array}$ & 3,13 & 2,99 & $13 \%$ & $13 \%$ & $39 \%$ & $19 \%$ & $16 \%$ \\
\hline
\end{tabular}

Fonte: Elaborado pelos autores (2013)

Aprendizagem em Equipe: Na Tabela 3, que apresenta o resultado dos questionários referentes à parte que se pretende diagnosticar a capacitação da empresa para a Aprendizagem em Equipe, verifica-se que a grande maioria dos funcionários (81\%), quando tem alguma dificuldade no trabalho, tem na empresa a quem solicitar orientação (a média mais alta desta parte do questionário - 4,00). Destaca-se também que as discussões na empresa são inteligentes e construtivas, sendo dentro das áreas $(3,71)$ de um nível superior a das entre áreas $(3,26)$.

Apontam-se, ainda, resultados abaixo da média quanto às dificuldades das áreas em colaborarem (ou não atrapalharem) com os trabalhos umas das outras $(3,10)$ e, inclusive, por não haver grupos de trabalho formados por profissionais de diferentes áreas para buscar soluções de problemas que afligem a todos (menor média desta parte do questionário - 2,61).

Mesmo não havendo consenso (desvio padrão de 3,66), outra dificuldade diagnosticada por esta pesquisa foi a inexistência de um sistema de feedback - ou seja, a empresa não orienta os funcionários em seu crescimento, pois não diz claramente onde estão errando ou acertando $(2,84)$. 
Tabela 3 - Respostas aos questionários relacionados ao Aprendizagem em Equipe

\begin{tabular}{|c|c|c|c|c|c|c|c|}
\hline APRENDIZAGEM EM EQUIPE & Média & $\begin{array}{l}\text { Desvio } \\
\text { padrão }\end{array}$ & 1 & 2 & 3 & 4 & 5 \\
\hline & 3,16 & & & & & & \\
\hline As discussões dentro da sua área são inteligentes e construtivas & 3,71 & 5,74 & $0 \%$ & $6 \%$ & $29 \%$ & $52 \%$ & $13 \%$ \\
\hline As discussões entre as áreas são inteligentes e produtivas & 3,26 & 5,00 & $3 \%$ & $16 \%$ & $35 \%$ & $42 \%$ & $3 \%$ \\
\hline $\begin{array}{l}\text { As áreas colaboram (ou não atrapalham) com os trabalhos umas das } \\
\text { outras }\end{array}$ & 3,10 & 4,62 & $6 \%$ & $16 \%$ & $42 \%$ & $32 \%$ & $3 \%$ \\
\hline $\begin{array}{l}\text { Existem grupos de trabalho formados por profissionais de diferentes } \\
\text { áreas para buscar soluções de problemas que afligem a todos }\end{array}$ & 2,61 & 3,37 & $23 \%$ & $19 \%$ & $39 \%$ & $13 \%$ & $6 \%$ \\
\hline $\begin{array}{l}\text { Quando você tem alguma dificuldade em seu trabalho, você tem na } \\
\text { empresa a quem solicitar orientação. }\end{array}$ & 4,00 & 6,01 & $0 \%$ & $6 \%$ & $13 \%$ & $55 \%$ & $26 \%$ \\
\hline $\begin{array}{l}\text { Existe um sistema de feedback (a empresa diz claramente onde você } \\
\text { está errando e/ou acertando) }\end{array}$ & 2,84 & 3,66 & $16 \%$ & $16 \%$ & $39 \%$ & $26 \%$ & $3 \%$ \\
\hline $\begin{array}{l}\text { Não é comum, nem bem vistas fofocas ou "puxada de tapete" } \\
\text { prejudiciais aos colegas }\end{array}$ & 2,61 & 2,32 & $32 \%$ & $16 \%$ & $19 \%$ & $23 \%$ & $10 \%$ \\
\hline
\end{tabular}

Fonte: Elaborado pelos autores (2013)

Visão Compartilhada: A Tabela 4, que apresenta o resultado dos questionários referente à parte que pretende diagnosticar a capacitação da empresa para a Visão Compartilhada, aponta acima da média que, entre os colegas de área, os funcionários percebem a liberdade para expressar as ideias livre e francamente $(3,81)$.

Mesmo sentindo-se motivados pela missão da empresa $(3,77)$, os respondentes afirmam que não sentem que todos os colegas estão juntos, querendo "ir para o mesmo lugar" $(2,94)$, afirmativa que teve baixo desvio padrão $(2,94)$ mostrando que nem todos pensam da mesma maneira sobre o assunto em questão.

Destaca-se aqui a afirmativa que ficou com pontuação na média $(3,42)$ e com alto desvio padrão $(6,43)$, significando que não se pode afirmar com certeza que existe coerência entre o que a empresa mostra para o mercado e o que realmente ela é por dentro e, ainda ficando abaixo da média $(3,19)$, a afirmativa de que não existe coerência entre o que a diretoria promete aos funcionários e o que a empresa faz.

Quando perguntado o que o motiva a continuar trabalhando na empresa, os mais votados foram, 34\% dos funcionários que preencheram o questionário responderam que gosta do trabalho que está fazendo; $21 \%$ dizem ter orgulho de trabalhar para a empresa (a marca); e 17\% identificam-se com os objetivos da empresa. Além destes, apareceu 12\%, que dizem gostar dos colegas; $11 \%$ estão satisfeitos com o salário; e 4\% salientam estar na empresa pela dificuldade de arrumar outro emprego. Apenas 1\% dos funcionários participantes da pesquisa disse ser outro motivo para continuar na empresa.

Tabela 4 - Respostas aos questionário relacionados ao Visão Compartilhada

\begin{tabular}{|c|c|c|c|c|c|c|c|}
\hline VISÄO COMPARTILHADA & Média & $\begin{array}{l}\text { Desvio } \\
\text { padräo }\end{array}$ & 1 & 2 & 3 & 4 & 5 \\
\hline & 3,43 & & & & & & \\
\hline $\begin{array}{l}\text { Existe liberdade para expressar as ideias, livre e francamente entre } \\
\text { seus colegas de área }\end{array}$ & 3,81 & 4,35 & $3 \%$ & $6 \%$ & $23 \%$ & $42 \%$ & $26 \%$ \\
\hline $\begin{array}{l}\text { Existe coerência entre o que a empresa mostra para o mercado e } 0 \\
\text { que realmente ela é por dentro }\end{array}$ & 3,42 & 6,43 & $10 \%$ & $0 \%$ & $32 \%$ & $55 \%$ & $3 \%$ \\
\hline $\begin{array}{l}\text { Você sente coerência entre o que a diretoria promete aos funcionários } \\
\text { e o que a empresa faz }\end{array}$ & 3,19 & 4,17 & $3 \%$ & $19 \%$ & $42 \%$ & $26 \%$ & $10 \%$ \\
\hline Você se sente motivado pela missão da empresa & 3,77 & 4,66 & $3 \%$ & $3 \%$ & $29 \%$ & $42 \%$ & $23 \%$ \\
\hline $\begin{array}{l}\text { Você sente que todos os seus colegas estão juntos querendo "ir para } \\
\text { o mesmo lugar" }\end{array}$ & 2,94 & 3,12 & $13 \%$ & $19 \%$ & $35 \%$ & $26 \%$ & $6 \%$ \\
\hline
\end{tabular}




\section{CONCLUSÃO}

Foi produzido, pelos autores, o Gráfico 1, o Radar de Capacitação Organizacional para a Aprendizagem, visando facilitar a visualização e consequente entendimento do desequilíbrio das vivências dos funcionários e quais técnicas precisam de mais atenção da organização. Por esse gráfico chamado de Radar de Capacitação Organizacional para a Aprendizagem, percebe-se que, na empresa estudada, há desequilíbrio entre as disciplinas essenciais, pois Domínio Pessoal alcançou a média de 3,53; Modelo Mental a média de 3,33; Aprendizagem em Equipe a média de 3,16; e a Visão Compartilhada a média de 3,43.

Esse desequilíbrio entre as disciplinas essenciais caracteriza a cultura organizacional estudada pela teoria de Senge (2006) como ainda não capacitada à aprendizagem, por ter enraizadas dificuldades principalmente na disciplina de Aprendizagem em Equipe. Lembrando que, segundo Senge (2006), as quatro disciplinas essenciais, conquanto desenvolvidas em separado, cada uma delas é essencial para o desenvolvimento da outra.

Como um sistema complexo, suas relações e inter-relações, quando promovidas em equilíbrio pela cultura organizacional, fazem nascer a quinta disciplina, o Pensamento Sistêmico. E como, no caso da empresa estudada, as quatro disciplinas essenciais estão em desarmonia, significa que, neste momento, a empresa tem dificuldades a superar para ser considerada empresa aberta à aprendizagem e, por sua vez, preparada ao enfrentamento dos desafios do mundo globalizado.

Gráfico 1 - Radar da Capacitação Organizacional para a Aprendizagem

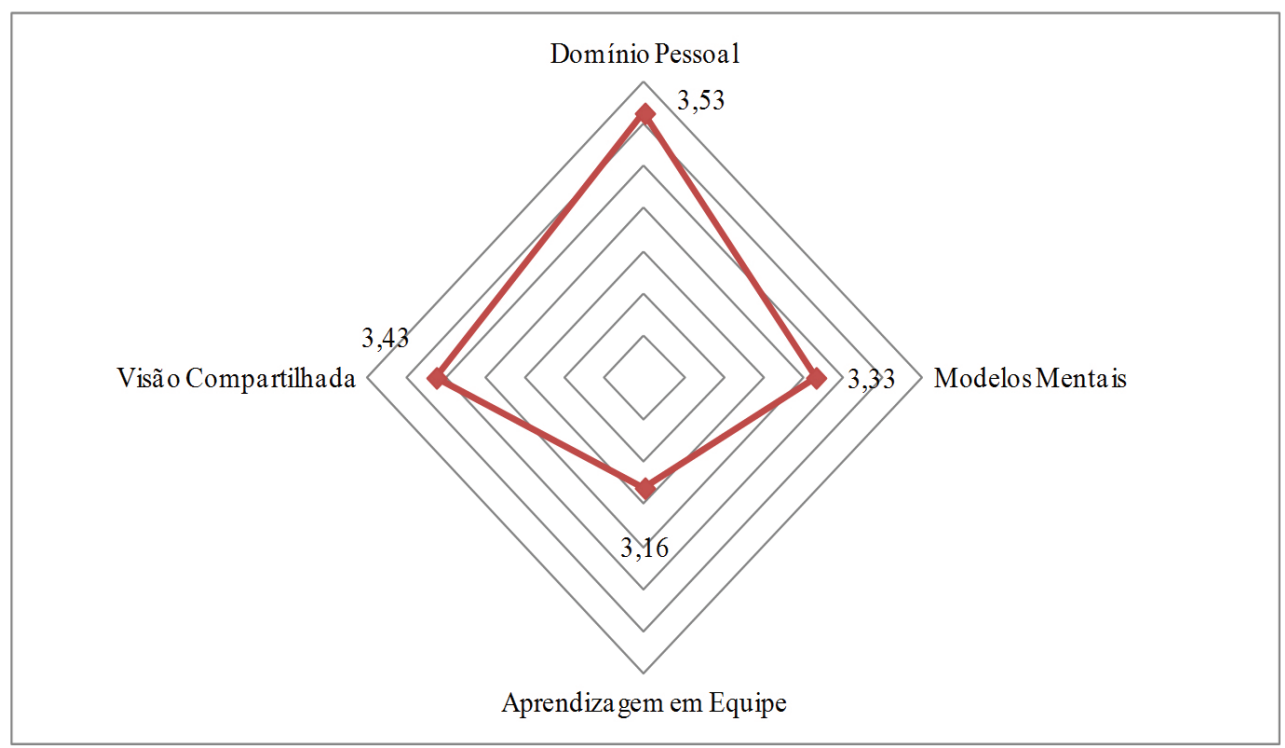

Fonte: Produzido pelos autores (2013)

A análise dos resultados das entrevistas com o dono da empresa estudada e dos questionários aplicados aos seus funcionários aponta que a maior deficiência cultural para a empresa posicionar-se quanto uma empresa aberta ao aprendizado são características voltadas a desenvolver a aprendizagem em equipe.

As dificuldades que devem ser foco de atenção para sua desconstrução e consequente conquista do equilíbrio desta disciplina são principalmente as seguintes:

1- As dificuldades de colaboração entre áreas é elemento provocador da falta de compreensão da complementariedade entre cada funcionário e seus colegas de área e, principalmente, com outras áreas. A Aprendizagem em equipe pressupõe a consciência da importância do outro para o alcance dos resultados pretendidos. Quando os funcionários buscam resultados individuais, não entendendo a importância da soma das forças individuais para a amplificação dos resultados de e para todos, a disciplina Aprendizagem em Equipe fica prejudicada, como é o caso da empresa estudada. A empresa não incentiva nem propicia trabalhos colaborativos, inclusive nem entre os próprios líderes, o que poderia construir hábitos de trabalhos colaborativos por meio de exemplos. Dessa forma, analisando-se os resultados, segundo a teoria de Senge (2006), conclui-se que estes são setoriais, e as soluções pouco inovadoras, visto que as buscas reduzem-se aos saberes de cada indivíduo ou de sua área específica. 
2- Como existem dificuldades de comunicação interna, em níveis e dimensões diversas, culminando com a falta de feedback, estas acabam por prejudicar inclusive as vantagens ativas na empresa da disciplina de Domínio Pessoal. Ou seja, a disciplina de Domínio Pessoal baseia-se na consciência do papel que cada funcionário representa para a existência e o crescimento da empresa e, por isso, quando identificada alguma deficiência de postura ou execução, o funcionário precisa ser orientado e motivado a buscar desenvolver competências, habilidades e atitudes pertinentes aos interesses da empresa. Quando o feedback não é realizado, além de não se construir um senso de equipe colaborativa, prejudica-se a melhora do desempenho de cada parte do sistema, danificando, assim, a disciplina de Domínio Pessoal.

o Radar construído facilita o alcance do objetivo desta pesquisa em diagnosticar o Estágio de Capacitação Interna para o Aprendizado. 0 Radar mostra claramente que a empresa estudada tem construído valor na disciplina Domínio Pessoal ao incentivar e apoiar os estudos e o crescimento individual. Quanto à disciplina de Visão Compartilhada, a empresa precisa dar mais atenção à comunicação interna e aos trabalhos colaborativos para que seja construída coerência entre as estratégias e as ações, o que, por sua vez, igualmente contribuirá para eliminar os bloqueios existentes na empresa com a finalidade de desenvolver a disciplina Modelos Mentais. A Aprendizagem em equipe é a disciplina com a média mais baixa, mostrando que a empresa tem trabalhado o incentivo e a motivação individual, não dando a devida atenção aos grupos e equipes de trabalho.

Assim, para o enfrentamento dos desafios do mercado globalizado que tem imposto crises aos sistemas organizacionais, será preciso passar a entender a sua complexidade, iniciando o gerenciamento da organização não mais por suas partes independentes (cargos, funções e operações), mas por meio de suas relações sistêmicas, diagnosticando as causas e visualizando caminhos e resultados, mesmo e principalmente, quando estes ultrapassam os limites setoriais e regionais, o que hoje é a base da sobrevivência globalizada.

\section{CONSIDERAÇÕES FINAIS}

Este estudo, além de um diagnóstico bastante contundente dos problemas vivenciados por uma pequena empresa brasileira da área de comunicação, destaca uma contribuição metodológica com seu questionário e o gráfico Radar para visualização do Estágio de Capacitação Organizacional para a Aprendizagem, que facilita o entendimento do diagnóstico e a discussão de soluções.

Sugere-se a realização de novas pesquisas com a aplicação deste questionário em outras pequenas e médias empresas brasileiras para mapeamento quantitativo da questão o que possibilitará a generalização das conclusões.

\section{DIAGNOSIS OF ORGANIZATIONAL CAPACITY FOR TEAMWORK}

\section{ABSTRACT}

The study envisioned the diagnosis of the capacity stage for learning of a Brazilian communications group. For this purpose, the study sought support from the theories of classical and contemporary authors, such as: Vygotsky (2005) and the social construction of learning, Morin (2006) and the concepts of complexity, and Nonaka and Takeuchi (1997) and the knowledge construction. Variables for analysis were defined based on the techniques for the "company that learns" by Senge (2006). A descriptive study was carried out predominately qualitatively through means of an interview and a documentary analysis and using survey questionnaires with the staff in order to obtain primary data. It was concluded that the group has built value for the Personal Domain discipline by motivating and supporting studies and individual growth; however, in order to enable it to face the challenges of globalization, it is necessary to give more attention to internal communication and to collaborative work. Thus,coherence was built between strategies and actions, which in turn, it will also contribute to the elimination of existing blocks in the group for developing other essential disciplines. This study, not only diagnosed the organizational capacity for learning, but also outlined the methodological contribution with its questionnaire and the spider graph, those which facilitate the understanding of the diagnostic and the discussion of solutions for the detected difficulties.

Keywords: Organizational Diagnostic. Organizational Learning. Knowledge construction. 


\section{REFERÊNCIAS}

HAYES, R. et al. Em Busca da Vantagem Competitiva: Produção, Estratégia e Tecnologia. Porto Alegre: Bookman, 2008.

MALHOTRA, N.K. Pesquisa em marketing: uma orientação aplicada. Porto Alegre: Bookman, 2001.

MATURANA, H. R.; VARELA, F. J. A Árvore do Conhecimento: as bases biológicas da compreensão humana. 6. ed. São Paulo: Palas Athena, 2007.

NONAKA, I; TAKEUCHI, H. Criação de Conhecimento na Empresa: Como as empresas Japonesas geram a Dinâmica da Inovação.18. ed. Rio de Janeiro : Elsevier, 1997.

SENGE, P. M. A Quinta Disciplina: Arte e Prática da Organização que Aprende. Rio de Janeiro: Best Seller, 2006.

VERGARA, S.C. Projetos e relatórios de pesquisa em Administração. 4. ed. São Paulo: Atlas, 2005.

VYGOTSKY, L. S. Pensamento e Linguagem. 3. ed. São Paulo: Martins Fontes, 2005.

WOOD, T.; ZUFFO, P. K. Supply Chain Management. Revista de administração de empresas (RAE), São Paulo, v. 38, n. 3, p. 55-63, jul./set. 1998. 